\title{
Calculation of PVC windows for wind loads in high-rise buildings
}

\author{
Aleksandr Konstantinov ${ }^{1, *}$ Maya Lambias Ratnayake ${ }^{1}$ \\ ${ }^{1}$ Moscow State University of Civil Engineering, Yaroslavskoye shosse 26, Moscow, 129337, Russia
}

\begin{abstract}
In the following article we examine problems faced when designing PVC windows for high-rise buildings, which are usually not considered when constructing objects for massive sites, using a high-rise residential complex as an example. We address the matters related to wind loads on windows \& statistical calculation of the impact of wind loads on them. We have presented variants of installing load-bearing elements of PVC windows which accept wind loads. We conducted a laboratory experiment by simulating wind loads on the window design, which is actually used for glazing the examined high-rise building. In the course of the experiment we determined additional factors which need to be considered when constructing PVC window structures for glazing high-rise buildings. We can determine that the following calculation method for the impact of wind load on PVC windows gives higher values of the desired statistical characteristics of load-bearing elements of a window compared to the results of laboratory experiments. We provide prerequisites to improve the analytical method of calculating impact of wind loads on loadbearing elements of PVC windows.
\end{abstract}

\section{Introduction}

Currently, the construction volume of high-rise buildings in the world is constantly increasing, especially in the residential sector [1-5]. To reduce the cost of construction of high-rise buildings, we introduce technologies which were previously used only in mass construction sites. One such example is using PVC windows when glazing high-rise buildings instead of using traditional aluminium windows. PVC windows have lower cost $\&$ have better thermotechincal characteristics compared to aluminium windows. Nevertheless, initially PVC window systems were designed to be used low-rise \& standard multistorey constructions. The use of PVC windows in high-rise buildings, which are subjected to high values of wind loads during construction \& operation, needs consideration as to the technological construction features of the PVC window system, as well as the structural concept, parameters \& the construction technology of the building. In the article we examine the questions of designing \& statistical calculation of PVC windows using a high-rise apartment building which is $140 \mathrm{~m}$ in height as an example.

\footnotetext{
* Corresponding author: apkonst@yandex.ru
} 


\section{Description of high-rise buildings. Description of the structural concept of windows}

The considered building is a 37-storey tower shaped in the form of a rhombus in the plan and the total height is $140.3 \mathrm{~m}$ (figure 1). The building is located in a densely built-up urban area. For glazing the building we use large-size structures of window units from the PVC profile. The designed window unit with load area of maximum collection of wind loads is presented in figure 1.
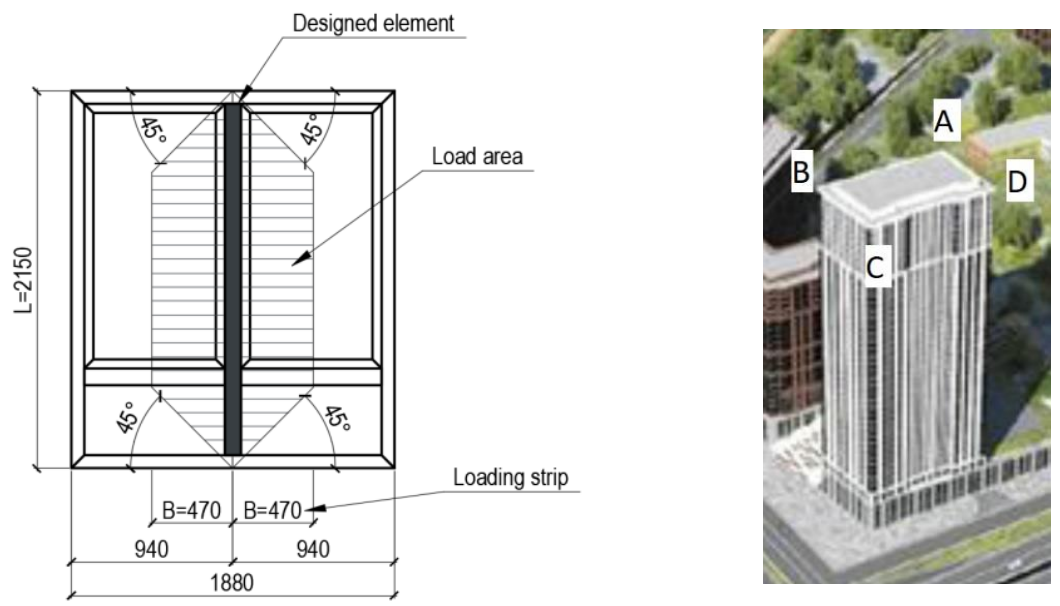

Fig. 1. Scheme of the designed window unit and General view of high-rise buildings and

\section{The function of wind loads on PVC windows of high-rise buildings}

The application of calculated values of wind loads of translucent structures in standard building construction sites are conducted according to valid normative documents $[6,7,8]$. During which, the calculated value of wind loads depend on the shape of the building, the wind area $\&$ the terrain type of construction area $\&$ it increases when the height of the building increases. For high-rise buildings using this approach is incorrect, as it does not take in to account formation features of air streams of high-rise buildings in their surrounding building area. For high-rise buildings it is essential to conduct a simulation of wind loads in laboratory conditions using an aerodynamic tube [9-12], or by using special software programs [13-16]. Research was conducted in the aerodynamic tube for the studied building to determine the actual wind load on the building. The results of simulation showed that the calculated value of wind loads on the building reach values in absolute magnitude equal to $\mathrm{W}_{\bmod }=1440 \mathrm{~Pa}$. Meanwhile, the calculated value of wind loads obtained from valid normative documents was equal to in absolute magnitude $\mathrm{W}_{\text {norm }}=2130 \mathrm{~Pa}$ (i.e. 1,4 times more). $\mathrm{W}_{\text {mod }}$ is adopted as the calculated wind pressure on windows of the building.

\section{Analytical calculation of PVC Windows for the impact of wind loads}

According to the valid normative documents $[8,17,18]$ statistical calculation for impact of wind loads on profile elements of the window unit are conducted according to conditions of inadmissibility of excessive infiltration of cold air. 
Required moment of inertia of load-bearing elements of the window unit are determined by formula 1

$$
J_{\text {req }}=\frac{W \cdot L^{4} \cdot B}{1920 \cdot E \cdot f}\left[25-40\left(\frac{B}{L}\right)^{2}+16\left(\frac{B}{L}\right)^{4}\right]
$$

$W$ - the calculated value of wind load, $\mathrm{N} / \mathrm{mm}^{2}$;

$B$ - width of loading strip in the stress diagram, $\mathrm{cm}$;

$L$ - working length of the load-bearing elements of the window unit, $\mathrm{cm}$;

$E-$ modulus of elasticity, Pa. For steel E $=210000 \mathrm{~N} / \mathrm{mm}^{2}$;

$f$ - maximum relative deflection of the load-bearing element of the window unit.

Maximum relative deflection of profile elements of window units are taken as equal to

$$
f=\frac{1}{300} L \text {. }
$$

It is considered that if the relative deflection of load-bearing elements of the window unit does not exceed the specified value, the wind does not blow through the window. For the window unit shown in figure 2 , the required moment of inertia of the vertical mullion will be $J_{\text {req }}=23.15 \mathrm{~cm}^{4}$.

\section{Technological limitations of PVC window systems}

The existing rules for the statistical calculation of PVC window units is based on the assumption that operational loads (wind pressure, own weight of the windows, etc.) occurs only by steel liners installed inside profile elements made of PVC.

We can provide the required characteristics of the design elements of large format PVC windows, based on the construction characteristics of the PVC window systems in two ways. In the first case, the large format window unit is divided into two parts \& a frontconnector is installed in between, which receives the wind load (see figure 2). In the second case the window unit is not broken into parts, but an external amplifier is installed in the vertical mullion (see figure 3). In an architectural \& structural point of view, the second option is optimal because using first option significantly reduces light transmission through the window.

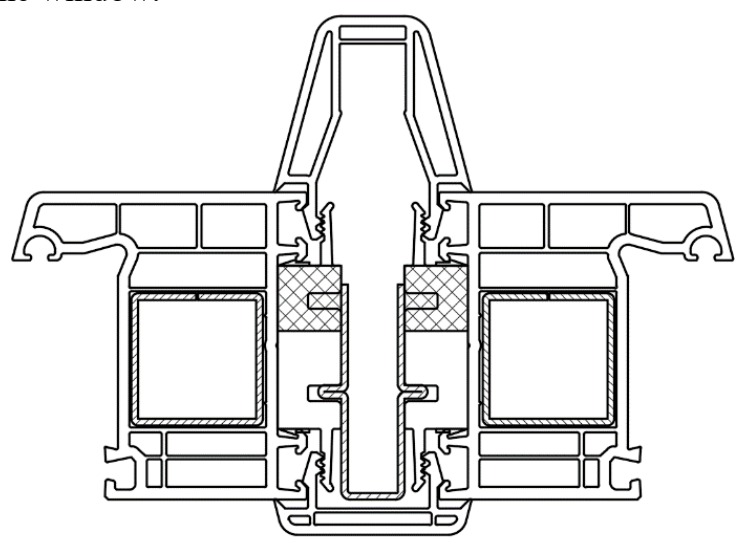

Fig. 2. Variant of strengthening PVC window units using front connectors

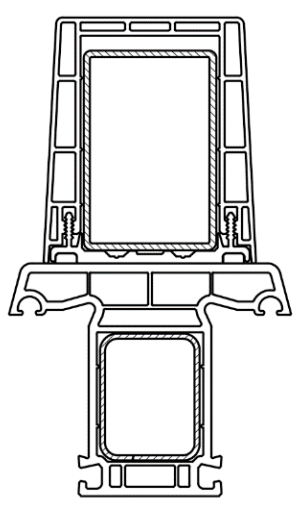

Fig. 3. Variant of strengthening PVC window units using external amplifiers.

For the considered case the actual value of the moment of inertia of a vertical mullion with an external amplifier, which is designed according to valid normative documents, is; 


$$
J_{r e q}=J_{i m p}+J_{s t}=2.68+18.87=21.55 \mathrm{sm}^{4}
$$

However, according to existing calculation methods when determining the actual moment of inertia of the mullion only the moment of inertia of the reinforcing liners are taken into account.

\section{Laboratory experiment on simulating the impact of wind loads on PVC window}

To determine the actual work of the adopted window structure under the impact of calculated values of wind pressure, a laboratory experiment was set up. The experiment was conducted on a special test stand to determine the operational performance of window units under the impact of excess pressure of air and atmospheric precipitation.

The test stand consisted of 3 basic units; test unit, control unit and computer unit. The test unit was a closed sealed chamber where the test sample is installed on one side. The control unit consisted a compressor to create positive or negative pressure inside the test unit, as well as a set of automatics and detectors to measure parameters such as temperature-humidity conditions inside the laboratory and operational factors of the test samples (permeability and resistance to wind loads). The Computer unit of the stand included a seat for the operator and the computer, which was used to determine the function of the testing program and to control the stand. To determine the relative deflections of the load-bearing elements of the window, the stand was equipped with electronic linear displacement detectors.

Before testing, the window unit was installed in a wooden frame. Fixating the window block in the frame (step and the installation of fasteners) was performed on the basis of valid standards $[8,19,20]$. General views of the stand with the installed test sample are shown in figures 6 and 7.

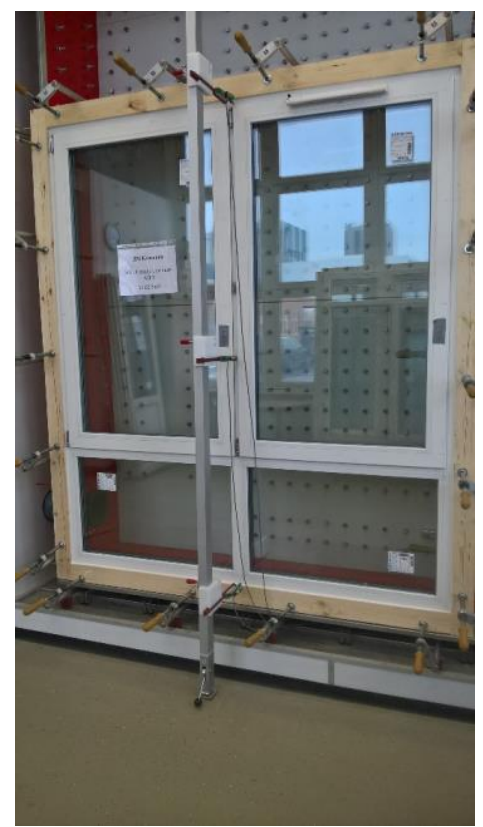

Fig. 4. General view of installed test window unit

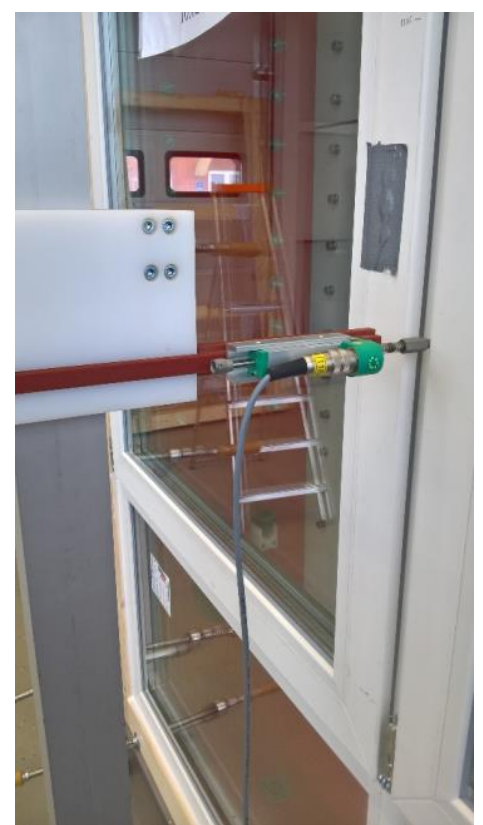

Fig. 5. Linear displacement detectors to determine the relative deflection of mullions 


\section{Analysis of the results}

As a result of the conducted experiment we found that when the window unit is under the impact of wind pressure equal to $\mathrm{W}_{\bmod }=1440 \mathrm{~Pa} \&$ the calculated actual moment of inertia was equal to $21,55 \mathrm{~cm}^{4}$, the deflection of the vertical mullion was $5.37 \mathrm{~mm}(1 / 400$ of the calculated length of the mullion, taken as equal to the height of the window unit). To ensure this relative deflection of the mullion, required moment of inertia of the mullion should be in accordance with the valid method of calculation (see formula 1) and equal to $30,86 \mathrm{~cm}^{4}$, which is $43 \%$ higher than the actual value. It is obvious that statistical calculation methods for PVC window units currently used by structural-designers allow the calculations to be made with redundant deflections. In order to reduce the cost of window units is necessary to optimize this technique.

It is observed that when the wind pressure is more than $600 \mathrm{~Pa}$, wind blows through the upper area of the hinges of window unit accompanied by a characteristic whistle. Wind blowing occurred due the contraction of upper hinges of the casement window sealing. Accordingly, in the course of the experiment we observed that - when relative deflections do not exceed normative values $(1 / 300 \mathrm{~L})$, we do not follow the basic calculation criterion of impact of wind loads on window units - thus, no wind blowing.

\section{Discussions}

According to the valid methodology [8], during the statistical calculation of mullions of PVC window units, only the rigidity of steel amplifier of the mullion is taken into account. The rigidity of profile of the mullion, as well as spatial work of the mullion with casement window is not included in the calculations.

It is proposed to develop a new method for calculating the impact of wind load on window units, which would take the above parameters in to consideration. We propose to conduct numerical modeling and a series of laboratory experiments in order to establish the actual work of window blocks of PVC by the impact of wind loads. It is proposed to conduct the research system for "mullion+casement window", which would take into account their work together under the impact of wind loads. The rigidity of the reinforcing liners as well as the rigidity of the translucent infill of PVC profiles should be taken in to account. On the basis of these subsequent studies, it is possible to form a refined analytical method to statistically calculate the impact of wind load on of PVC window units.

\section{Conclusions}

We compared the existing methods for calculating the impact of wind loads on PVC window units with the results of laboratory tests of the actual design of the window unit. It was determined that in the existing method for calculating the impact of wind loads on PVC window units includes a considerable redundancy for rigidity (40\%). It is established that when the wind pressure is above $600 \mathrm{~Pa}$, while meeting regulatory requirements for deflections, we can observe wind blowing through upper hinges of window units. When installing PVC window frames in high-rise buildings we recommend the using concealed hinges.

We propose a new method of calculation to determine the impact of wind loads on window units which would take into account the collective work of the constituent elements of the window unit (reinforcing liners, window profiles with translucent infill, etc.) in order to reduce the cost of manufacturing window units by using reinforcing profiles of smaller cross section. 


\section{References}

1. E. Generalova, V. Generalov, CTBUH, 4, 40-45 (2014)

2. L. Sedegova, Vestn. Dona, 2(25), 123 (2013)

3. E. Generalova, V. Generalov, Social, humanitarian, medicobiological sciences, 16, 458-463 (2014)

4. Nechaeva, Gorneva, The Fourteenth International Scentific Conference Proceedings, 1, 268-275 (2014)

5. V. Shpara, Modern trends in design and constructing high-rise complexes, 1-2(8), 7-8 (2013)

6. EN 1991-1-4:2005+A1:2010

7. Russian State Standard SP 20.13330.2016

8. Russian State Standard GOST R 56926-2016

9. M. Mikhaylova , V. Dalinchuk, A. Bushmanova, L. Dobrogorskaya, Construction of Unique Buildings and Structures, 10, 59-74 (2016)

10. Povzun, Buzun, Zimin, Construction of Unique Buildings and Structures, 3(30), 7080 (2015)

11. Poddaeva, Dunichkin, Industrial and civil engineering, 4, 42-45 (2016)

12. A. Kubilay, D. Derome, J. Carmeliet, Building and Environment, 114, 68-81(2017)

13. A. Kubenin, A. Fedosova, Scientific Review, 8, 130-135 (2015)

14. A. Kubenin, A. Fedosova, Scientific Review, 8, 136-141 (2015)

15. S. Isaev, P. Baranov, Y. Zhukova, A. Tereshkin, A. Usachov, Journal of engineering physics and thermophysics, 87, 112-123 (2014)

16. O. Poddaeva, S. Dubinsky, A. Fedosova, Industrial and civil engineering, 9, 23-27 (2014)

17. DIN 18055:2014-11

18. DIN EN 14351-1:2016-12

19. Russian State Standard GOST 30791-2012

20. Russian State Standard GOST 30674-99 